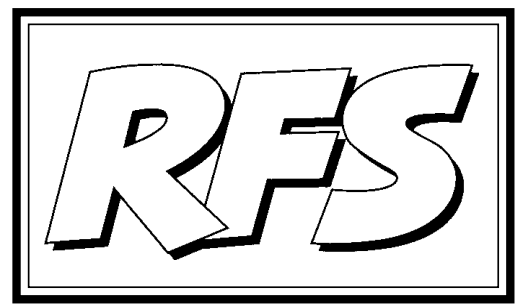

Revista de Fomento Social, 53 (1998), 427-440

\title{
La deuda externa hoy
}

En relación con el llamado «Jubileo 2000», está en marcha una campaña a favor de la condonación, con ciertas condiciones, de la deuda externa de los países más pobres. Nuestros lectores encontrarán en el artículo siguiente un buen compendio del proceso de endeudamiento de los países del Tercer Mundo, de las iniciativas surgidas a lo largo de los años para paliar el grave problema de la deuda externa, de los foros internacionales en que se negocian las alternativas existentes y de la situación de España como país acreedor. El artículo viene seguido de un interesante documento sobre la cuestión de CIDSE y Caritas Internationalis (1).

Javier GOROSQUIETA REYES S.J. (*)

(*) Profesor de ICADE. Universidad Pontificia Comillas (Madrid).

(1) Véase sobre el origen del problema en nuestra misma revista I. CAMACHO: «La deuda exterior del Tercer Mundo. Aproximación ética a los hechos y a las soluciones». Revista de Fomento Social, no 166, abril-junio 1987, pp. 133-152. 


\section{El origen de la deuda externa}

Siempre ha habido deuda externa, pero en estas líneas me quiero referir a la que se produjo en el planeta a partir de los primeros años 70, muy especialmente a partir del estallido de la crisis del petróleo en el otoño de 1973.

Como es bien sabido, desde 1973 aumentó sustancialmente la liquidez monetaria internacional. Dos fueron las causas principales de este incremento: la primera, el crecimiento espectacular del déficit público estadounidense por aumento de los gastos corrientes en aquel país y como consecuencia de los desembolsos derivados de la guerra del Vietnam. La segunda, las enormes corrientes de «petrodólares» hacia los países productores del «oro negro», particularmente hacia los países árabes. Estados Unidos se endeudó para cubrir sus déficits. Los pagos del servicio de su deuda (amortización e intereses) inundaron de dólares los mercados internacionales y los depósitos bancarios en la divisa norteamericana. Por su parte los «petrodólares», o dólares procedentes de las ventas de petróleo, fueron depositados en grandes cantidades en los bancos del Occidente desarrollado. Y como el negocio bancario consiste, en buena medida, en prestar más caro lo que se recibe en forma de depósitos a bajo tipo de interés, esos bancos occidentales tenían una necesidad perentoria de dar créditos para apuntalar sus cuentas de resultados. Así prestaron en especial a los Países en Vías de Desarrollo (PVD).

Como el tema de la deuda hodierna tiene más de 25 años de historia, tras la indagación en la misma hoy se está plenamente de acuerdo en que esos bancos dieron créditos un tanto alegremente, sin las debidas garantías, en concreto a los PVD. Por eso hoy se los considera corresponsables de la crisis mundial de la deuda.

En cuanto a los PVD, su necesidad perentoria estaba en tomar prestado para invertir dentro de una política de desarrollo, de erradicación de la pobreza, de la miseria frecuentemente. Así lo hicieron en grandes volúmenes, aprovechando la buena disposición de los bancos internacionales y confiados en el buen momento de los precios de sus materias primas exportables. Pensaron, es de creer, que podrían hacer frente al pago periódico del servicio de su deuda con los ingresos procedentes de sus exportaciones y de la propia dinámica del crecimiento económico interno. Emprendieron importantes proyectos de crecimiento sin reparar en los gastos, y así también se endeudaron en el mercado internacional 
por encima de sus entonces cuantiosas ganancias.

Pero sucedió que los países desarrollados, muy golpeados por la muy brusca subida de los precios del petróleo desde 1973, entraron en una recesión económica y comenzaron a comprar menos a los PVD ya endeudados. Además, pusieron en práctica una exitosa política de ahorro energético y de materias primas naturales, una política industrial menos dependiente del petróleo y de aquellas materias primas. Estas últimas fueron siendo sustituidas en buena parte por productos sintéticos (caucho sintético por caucho natural, fibras textiles sintéticas por la lana y el algodón, etc.). Con ello los PVD fallaron en sus demasiado optimistas cálculos de ingresos.

Y vino la explosión del problema de la deuda. Sucedió en 1982 cuando Méjico anunció que necesitaba una moratoria en sus pagos internacionales. Hasta muy cerca de este anuncio no hubo consciencia en el sistema financiero del problema que se avecinaba. Prueba de ello es que tan sólo tres meses antes de dicho anuncio, Méjico recibió de los grandes bancos británicos un cuantioso crédito sindicado (de un grupo de bancos de mutuo acuerdo) -de los llamados créditos «jumbo»-por un importe de mil millones de dólares USA.

Tras Méjico otros países fueron cayendo, como fichas de dominó, en la lista de aquellos que necesitaban retrasar sus pagos para poder afrontarlos. Se planteaba también una situación de auténtica emergencia para la banca comercial internacional. Era tal su grado de exposición al riesgo, que un impago de los países endeudados podía hacer quebrar a algunos de los bancos más fuertes del sistema financiero, produciendo en el mismo un crack sin precedentes. Los precios del petróleo en esta ocasión, a partir de 1981, frenaron su crecimiento, lo que sorprendió a algunos países exportadores que, como Méjico, habían contado con los beneficios futuros al endeudarse, apareciendo expectativas más oscuras aún de lo que se podía prever.

De lo dicho hasta ahora se deduce que, en su origen, hubo dos protagonistas corresponsables del problema actual de la deuda: los bancos del Norte desarrollado, por un lado, y los PVD por otro.

Se inició entonces, a partir de 1982, la búsqueda frenética de soluciones. Y espero quede claro a lo largo de este escrito que se han ido salvando, con el tiempo, los intereses generales de los acreedores pero no los de las poblaciones empobrecidas del Sur, principales afectados en sus carencias económicas más vitales. 
Según Jaime Atienza (2), los pricipales factores relevantes que pudieron contribuir a que fuesen los intereses de los acreedores los dominantes desde el comienzo de los impagos, son los siguientes:

- El mayor poder, respaldo y credibilidad de las entidades acreedoras involucradas ante las Instituciones Financieras Multilaterales (IFM) (Fondo Monetario Internacional (FMI) y Banco Mundial (BM)), que polarizaron la resolución de la crisis del sistema bancario sobre las del endeudamiento de los PVD.

- La falta de peso específico de los países endeudados en el concierto internacional: se trata de países periféricos, con un limitado nivel de influencia; su situación de subdesarrollo les hace carecer de fuerza negociadora internacional.

- El déficit democrático de muchos de los países endeudados limitaba su actuación y peso negociador por la falta de legitimidad internacional, al igual que al interior de sus países.

- La unión y la unidad de criterios con la que actúan los acreedores y, al contrario, la falta de unidad de criterios y de actuación de los países endeudados (nos queda la pregunta de si esta desunión fue fruto de su incapacidad de conseguir posiciones de fuerza conjuntas o más bien inducida por el grupo que defendía intereses enfrentados). A ello podemos unir la indudable ausencia de posicionamiento y oposición firme y conjunta de los deudores a las propuestas y planes -o a partes de los mismos-que podían ser consideradas discutibles y perjudiciales.

\section{Las distintas iniciativas surgidas ante el problema de la deuda}

a) De 1982 a 1986

La filosofía fue prestar más dinero a los PVD para que, con el dinero fresco, pudieran ir devolviendo las deudas anteriores. Pero en estos nuevos préstamos se

(2) J. Atienza Azcona (1998): La deuda externa y los pueblos de Sur. Editan Manos Unidas, Caritas, CONFER, Justicia y Paz. Madrid. P. 43. Sigo esencialmente este libro en el desarrollo de la parte central de este artículo. Puede verse también J. REQueIJo(1995): Economía Mundial, McGraw Hill. Madrid. Pp. 147-191. 
impuso la «ortodoxia bancaria»:

- el nuevo préstamo, por ser a mayor plazo y para un mal pagador, tenía un tipo de interés más elevado;

- asimismo, se cobrarían nuevas comisiones por su concesión.

Esta política, si bien permitió ganar tiempo a los acreedores, resultó nefasta para los países endeudados. ElFMI, supervisor de las primeras rondas de negociaciones, trató de condicionar los nuevos créditos a la aceptación por los PVD de los llamados Planes de Ajuste Estructural (PAE). Éstos pretendían esencialmente disminuir los gastos, públicos y privados, de los PVD, con lo que disminuirían sus importaciones y, por lo tanto, la necesidad de divisas para sufragarlas. Como, por otro lado, recibían, en divisas, el dinero fresco de los nuevos créditos se pensaba que, por esos dos capítulos, dispondrían de los dólares necesarios para ir devolviendo la deuda. Como dijo por aquellos tiempos elex-presidente argentino Alfonsín, «quieren que devolvamos la deuda con el hambre de los argentinos».

No salieron los cálculos ni podían salir. Se deterioraron, por el contrario, las situaciones macroecnómicas de los PVD ya que, por un lado, por culpa de los PAE, no podían importar lo necesario para su desarrollo interior, ni podían expandir la demanda nacional, con lo que entraron en un proceso recesivo las empresas y la producción ya que, si no responden los mercados comprando, las empresas productoras, y el empleo, se retraen produciendo menos. Por otra parte ya hemos hablado de la crisis de las exportaciones, potencial fuente de divisas, de los PVD.

El resultado final fue que los acreedores fueron viendo devueltos, más o menos, los créditos otorgados, pero que se disparó la deuda de los PVD.

Para ver esto con mayor claridad conviene distinguir cuatro tipos de deuda:

- Deuda comercial. Los acreedores comerciales son aquellas entidades de orden privado (desvinculadas del Estado) y con ánimo de lucro, con las que, fruto de operaciones comerciales, financieras, crediticias o de otro orden contrajeron deudas los PVD. El principal componente de este grupo de acreedores es la banca. Según datos de la OCDE, la deuda a corto plazo de los PVD con la banca privada ascendía en 1995 a 423.000 millones de \$USA (más del 80\% de la deuda a corto plazo).

- Deuda bilateral.Los acreedores son los Estados que han mantenido relaciones directas financieras, comerciales o de otro tipo con PVD y que, como consecuencia de las mismas, se han convertido efectivamente en sus acreedores. A lo largo del periodo que podemos llamar de «gestación de la 
crisis de la deuda» la participación de los Estados como prestamistas o financiadores de operaciones se encontraba principalmente vinculada con créditos a la exportación para facilitar operaciones de las empresas del país exportador, bien mediante seguros de créditos a la exportación o, de manera marginal, con créditos directos gobierno-gobierno.

- Deuda proveniente de la Ayuda Oficial al Desarrollo(AOD). Esta AOD puede ser no reembolsable, concesional, regalada, por lo que, por este capítulo, no se incrementa la deuda de los PVD. Pero hay otra AOD reembolsable (en España la constituida por los Fondos de Ayuda al Desarrollo o créditos FAD). En este último caso y en España la Compañía Estatal de Seguros de Crédito a la Exportación (CESCE) asegura a las empresas privadas españolas exportadoras el cobro, en el peor de los casos, del $97 \%$ de los créditos que hubieran podido dara PVD para facilitar sus propias exportaciones. Finalmente, pues, el supuesto PVD inicialmente fallido se convierte en deudor de la CESCE, en definitiva del Estado español. La CESCE también ofrece cobertura a los llamados riesgos políticos (incertidumbres o inseguridad política en el PVD importador) en operaciones de crédito a la exportación. La suma de la deuda bilateral y de la AOD constituye en la actualidad el 47\% del total de la deuda a largo plazo, con 623.000 millones de dólares. Es, hoy en día, la deuda de mayor peso de los PVDy su participación en el total mundial ha sido constantemente creciente (desde el $42 \%$ en 1986 hasta el $47 \%$ en 1995)

- Deudas multilaterales. Son las contraídas por los PVD con las Instituciones Financieras Multilaterales (IFM), como son el FMI, el BM y los Bancos Regionales de Desarrollo. Su peso sobre el total de la deuda a largo plazo ha sido creciente. En concreto, ha pasado de 174.000 millones de dólares en 1985 (el 19\% del total) a 326.000 millones de dólares en 1995 (el 24\%).

El papel de las IFM como acreedoras ha sido creciente para los países más pobres, por las dificultades de estos para conseguir finaciación comercial y, en menor medida, bilateral.

Las IFM fueron otorgando financiación a los países que cumplían con rigor los programas de ajuste y fueron dotando sucesivos fondos para los países con mayores problemas de pagos internacionales y de balanza de pagos. Así, la financiación de las IFM se convirtió en un elemento decisivo para muchos de los países endeudados, una vez reducidos en gran parte los créditos del sector bancario 
(que únicamente se otorgaban ya con el objeto de evitar impagos inmediatos con los nuevos créditos). Los países con mayores problemas estructurales acabaron quedando también al margen de la financiación tradicional del Fondo y del Banco, para tener acceso tan sólo a la llamada «ventanilla blanda» del Banco Mundial: la Agencia Internacional de Desarrollo(IDA), que otorga una financiación concesional, mucho más limitada

\section{b) El plan Baker y el plan Baker II}

Tras una primera etapa, en septiembre de 1985, el Secretario del Tesoro estadounidense presentó, en el marco de las reuniones del FMI y del BM un nuevo programa para el tratamiento de la deuda externa. En la línea del enfoque inicial, el llamado Plan Baker I mantenía el objetivo principal de sostener los compromisos de los deudores pero mejorando sus condiciones de liquidez y solvencia (para lo que eran necesarios nuevos créditos y crecimiento económico). En el mismo se afirmaba que los deudores no podían sacrificar su crecimiento económico para afrontar sus pagos internacionales, y se pedía a los bancos y países acreedores una actuación más generosa para conceder liquidez. Se asumía el círculo vicioso según el cual sin crecimiento se ponía en peligro el cumplimiento de las obligaciones finacieras internacionales, y sin nueva financiación se hacía difícil el crecimiento. Este Plan proponía a la banca comercial el lanzamiento de instrumentos que pudiesen serútiles en el tratamiento de la deuda. Aparecieron asílos intercambios de deuda por activos, la recompra de títulos de deuda y los llamados bonos de salida titulares también de deuda.

El fracaso de esta iniciativa se debió -al margen de las limitaciones de sus propuestas-tanto al retraso de la puesta en marcha de dichos instrumentos como a la tardanza de la financiación multilateral y comercial que, por otro lado, llegó en montos inferiores a los previstos. La consecuencia inmediata de ese fracaso para poner en marcha una senda de crecimiento y estabilidad financiera, fue el incumplimiento de la primera premisa del Plan: el pago de los intereses de la deuda por parte de los países endeudados. Ante la evidencia de estos nuevos impagos, las partes acordaron diferir en el tiempo las amortizaciones y otorgar nuevas líneas de crédito para evitar, por una parte, el desmoronamiento de las economías de los países deudores y, por otro lado, interrupciones en los pagos de los intereses, que tendrían nefastas consecuencias para la banca privada, en especial la norteamericana. 
A lolargo de estos años, el sector bancario fue recuperando estabilidad mientras los Estados endeudados no mejoraron su situación; podría afirmarse que la estabilidad del sistema financiero se alcanzó a costa del deterioro de la situación socioeconómica de los PVD deudores.

Ante la insuficiencia de sus propuestas, el propio James Baker presentó nuevas medidas en la reunión del FMI de 1987 (lo que se llamó el Plan Baker II), en las que aparecen los llamados «mecanismos voluntarios de reducción de deuda»además de los tres instrumentos arriba mencionados. Por una parte los acreedores incrementarían sus expectativas de cobro aunque en menorimporte y los deudores conseguirían suavizar las condiciones del pago del servicio y disminuir su cuantía. Se admite, pues, en las IFM de manera implícita la existencia de una crisis de sobreendeudamiento (y no sólo de liquidez como se había mantenido hasta entonces) y la necesidad de introducir más elementos concesionales.

\section{c) El Plan Brady}

El Plan Brady, ex-Secretario de Estado norteamericano, nació en 1989. Sus novedades principales son dos: primera, la llamada «titulización» de la deuda externa. La deuda externa se representó no sólo en los libros de contabilidad de los acreedores sino también en unos títulos denominados bonos. Estos bonos eran vendibles en los mercados financieros y normalmente se vendieron en los mismos a un valor inferior a su valor facial o nominal. La diferencia en los mercados entre estos dos valores era tanto mayor cuanto peor fama de pagador tuviera el deudor. No sólo se pretendió liberar así deuda antigua, sino que este Plan recomendó tanto a los Estados acreedores, como a las IFM como incluso a los bancos comerciales insuflar nuevo dinero en la economía de los países de renta media altamente endeudados, con el fin de que pudieran ir devolviendo la deuda vieja y sus intereses y, al mismo tiempo, crecer y hacer sus economías más competitivas. Con ello su capacidad de pago y de reembolso de la deuda, vieja y nueva, se incrementaría. Está claro que esta práctica, negociación de los bonos por debajo de su valor nominal, significó en la práctica una quita de la deuda, una renuncia por parte de los acreedores a recuperar la totalidad de su valor nominal.

La segunda gran novedad del Plan Brady fue la garantía que dio el Tesoro norteamericano de salir responsable subsidiario del pago de los bonos y de sus intereses vencidos, que fueron capitalizados. 
Fueron bonos con vencimiento a largo plazo, pero que gozaron, gracias sobre todo al respaldo norteamericano, de una gran liquidezen los mercados financieros.

A la experiencia de los bonos Brady se la considera como un éxito, si bien el escaso peso de los bonos (no solamente los Brady) en el volumen total de la deuda hizo que sus consecuencias no mejorasen sustancialmente el problema de la deuda externa en su conjunto. En efecto, la deuda total en bonos en el año 1995 ascendía tan sólo al 7,95\% del total acumulado. Sí tuvieron una relevancia decisiva en relación con la reducción del volumen total de la deuda comercial.

\section{d) La iniciativa PPAE (Países Pobres Altamente Endeudados)}

Fue lanzada por el FMI y el BM en abril de 1996 y aprobada en septiembre de ese mismo año. Su objetivo explícito es reducir a un nivel «sostenible» la deuda exterior de los países más pobres y endeudados.

Se considera deuda sostenible aquella que cumple estos dos índices o ratios:

- El Valor Actual Neto (VAN) del índice volumen de deuda/exportaciones, alcanza un nivel de entre $200 \%$ y $250 \%$ o inferior.

- El VAN del índice servicio de la deuda/exportaciones se sitúa entre un $20 \%$ y un $25 \%$.

Para alcanzar estos niveles, en una primera etapa se han de producir reducciones de deuda comercial y bilateral en primer lugar -alcanzando porcentajes de reducción de deuda hasta del $80 \%$-y, porúltimo y de manera residual, reducciones de la deuda multilateral.

La puesta en marcha de la iniciativa está condicionada al cumplimiento exitososo de Planes de Ajuste estructural por parte de los países elegibles durante los seis años que, como máximo, debe durar la ejecución de la iniciativa.

Es aún pronto para hacer una evaluación de esta iniciativa, pero ya han aparecido numerosas trabas, siendo las principales las reticencias a financiar la iniciativa por parte de algunos miembros del G-7 (Alemania y Japón en particular), la tardanza en su puesta en marcha para muchos de los países elegibles, y la práctica exclusión de otros de los beneficios de la misma. Por otra parte se le critica que haya puesto demasiado alto el listón de las dos ratios señaladas. Un ejemplo de la deuda que un Estado puede asumir nos lo dan los criterios de la Unión Europea: el 60\% del PIB. No parece razonable que para economías más débiles y problemáticas ese nivel de deuda «sostenible»se 
sitúe entre el $200 \%$ y el $250 \%$ de las exportaciones. Otro ejemplo podemos encontrarlo en el nivel de pagos que se exigió a Alemania tras la segunda guerra mundial como reparaciones de guerra: su límite superior era del 5\% de las exportaciones, mientras que, en esta iniciativa ese mismo nivel se situaba entre el $20 \%$ y el $25 \%$.

\section{Foros de negociación sobre la deuda externa}

\section{El Club de París}

El llamado Club de París es el club en el que se reúnen los principales Estados acreedores para tratar los problemas de pagos de los países deudores de manera global y no de forma bilateral. El Club no tiene estatutos, personalidad jurídica o instituciones que lo controlen. Sí que existen, en cambio, leyes «no oficiales» que se aplican de manera general y se aplican como un pacto entre caballeros. Esto supone que existe un margen de flexibilidad para adaptarse a las necesidades del país deudor, pero también es una puerta abierta a la subjetividad en el trato de favor a ciertos países.

Los dos factores fundamentales que condicionan las renegociaciones en elClub de París son:

- La existencia de un peligro inminente de impagos.

- La condicionalidad delFMI.

Es decir, los países que desean obtener una reestructuración de su deuda externa deben mostrarse incapaces de atender correctamente el servicio de la misma y deben haber adoptado un programa de ajuste en el marco de un acuerdo con el FMI. La deuda que se reestructura en el Club de París no es la estrictamente comercial privada sino la comercial y bilateral con cobertura pública (por ejemplo a través, en España, de la Compañía Estatal de Seguro de Crédito a la Exportación (CESCE)). No entra aquí tampoco, en España, la Ayuda Oficial al Desarrollo (AOD) ni los llamados créditos FAD (Fondo de Ayuda al Desarrollo).

Un principio fundamental de estas negociaciones de reestructuración es la comparabilidad en el trato otorgado por todos los acreedores. Con él se pretende lograr que exista equidad en el reparto del esfuerzo financiero que realizan todos los grupos de acreedores.

En estas negociaciones existen, evidentemente, elementos concesionales. 


\section{El Club de Londres}

Al contrario que el Club de París, el Club de Londres no llega a ser un foro estable propiamente tal. Más bien identifica a todo el proceso de renegociación de la deuda de un país con la banca internacional. Los acreedores son exclusivamente aquí los banqueros. El Club de París está planteando niveles de condonación de la deuda de entre el $67 \%$ y el $80 \%$ y es posible que la banca, en el Club de Londres, no tenga voluntad de asumir semejantes costes.

En cuanto a la toma de decisiones, en el Club de Londres se hace por consenso, como en el Club de París, aunque por la propia naturaleza del Club no se da publicidad a sus conclusiones.

3. La deuda con las IFM se reestructura en relación directa del país deudor con ellas. Se suele poder acceder a nuevos créditos, con elementos concesionales muchas veces, «blandos», pero, como queda dicho, estas concesiones de nuevas ayudas, créditos, suelen estar condicionadas a la puesta en práctica por el país prestatario de Planes de Ajuste Estructural que el propio FMI diseña.

4. En cuanto a la AOD, incluidos, en España, los créditos FAD, los Estados son libres para condonarlos, reestructurarlos o convertirlos a su libre albedrío.

\section{Volumen de la deuda externa}

A pesar de todos los mecanismos y renegociaciones señalados la verdad es que la deuda externa de los PVD ha ido ininterrumpidamente aumentando. Ésta es la realidad, aunque se hable ahora menos de la deuda que durante la virulencia de la crisis a lo largo de los años 80 . La deuda total ha pasado de 1,152 billones de dólares en 1986 a 1,985 billones de dólares en 1996. Y han subido ininterrumpidamente todos los capítulos de la deuda: bilateral, comercial, multilateral. Algo parecido ha sucedido con el servicio de la deuda: en 1986 era de 131.000 millones de dólares, en 1996 asciende a 206.000 millones de dólares.

En cuanto a la deuda de la que España es acreedora, deuda pública y privada, la cifra oficial que ofrece la OCDE asciende a 30.500 millones de dólares (3.992.145 millones de pesetas). Respecto de la deuda bilateral oficial española a largo plazo, ésta ascendía, en 1996, según el Ministerio de Economía y Hacienda, 
a 1.608.231 millones de pesetas. De esta última cifra, sólo el $42 \%$ aproximadamente (ca.675.450 millones de pesetas) era ayuda concesional (proveniente de créditos de AOD). El total de esa deuda bilateral oficial equivale al 2,2\% de nuestro PIB.

\section{Posibilidades de condonación por parte de España}

España es libre para condonar las deudas provenientes de la AOD (créditos FAD). Esta condonación equivaldría al 0,9 del PIB.

120 ONGs -encabezadas por Caritas, Confer, Justicia y Paz y Manos Unidashan lanzado en Europa, España incluida, una gran campaña para la condonación de la deuda a los PVD (3). Desde la ética de lo mejor y la solidaridad es necesario apoyar tal campaña. España dedica ahora en ayuda al desarrollo, incluidos los créditos FAD, sólo el 0,24\% de su PIB. Estamos muy lejos de aquel compromiso adquirido en Naciones Unidas, de alcanzar anualmente el 0,7 del PIB. Es preciso acercarse a él. El camino de la deuda bilateral oficial puede ser muy pertinente y válido.

En cuanto a la deuda bilateral oficial española no concesional (deuda comercial privada avalada oficialmente), estamos vinculados al pacto de caballeros del Club de París. Pero España en el Club de París debería tener una actitud generosa y podría presionar en esa línea a consensos globales.

Respecto de la mera deuda comercial privada, especialmente aquella de la que los bancos son acreedores, estimamos que los mercados secundarios de la deuda pueden jugar un papel importante. Porque una deuda sólo vale su importe por la probalidad de cobrarla. Y esto lo reflejan los mercados secundarios. Si deben a un banco 1.000 millones, pero sólo tiene un $50 \%$ de probabilidad de cobrarlos, es perfectamente lógico que ese banco esté dispuesto a vender esa deuda, si encuentra comprador, por sólo 500 millones. ¿Robo al banco? Creo que nada de eso en el caso que nos ocupa de la deuda externa, porque, como decíamos al principio, en el origen de esta deuda hay una responsabilidad compartida: la alegría y el riesgo bancarios en prestar y el error de cálculo de los PVD sobre sus posibilidades de devolverla. Bueno sería además que en el Club de Londres-que, imitandoal Club de París, asume el principio de la «comparabilidad de trato»-, se otorgaran

(3) Véase a continuación el documento «La vida antes que la deuda». 
parecidos porcentajes concesionales. Esto es tanto más sólido cuanto que, en previsión de insolvencias, los bancos ya las «provisionaron» en sus contabilidades; de aquí que deuda más o menos imprevisiblemente devuelta pase íntegra como beneficio a la cuenta de Pérdidas y Ganancias. Se acabaron, salvo posibles excepciones, los riesgos de quiebra bancaria.

Finalmente, es preciso dejar de someter prioritariamente los Planes de Ajuste Estructural, impuestos por el FMI como condición para recibir nuevos préstamos del mismo, a los intereses de los acreedores bancarios y bilaterales. Quienes más han sufrido con toda la crisis y el proceso evolutivo de la deuda externa han sido las poblaciones pobres o miserables de los PVD. Conviene ya, desde el reconocimiento de sus derechos humanos elementales, tener prioritariamente en cuenta sus necesidades de supervivencia y desarrollo.

\section{¿Condonación o conversión?}

Oí hace poco una conferencia a un ex-rector de una universidad en un país iberoamericano sobre el tema de la campaña aludida «Deuda externa ¿deuda eterna?». E hizo, entre otras, una afirmación categórica: «no soy partidario de la condonación sino de la conversión de la deuda». Su argumento: no siempre son de fiar las oligarquías políticas y económicas dominantes en no pocos PVD; y existe el riesgo de que se embolsen privadamente o de que derrochen y malgasten la deuda condonada, sin beneficio ninguno o con beneficios muy exiguos para las masas pobres del país. Por eso pensaba preferible renunciar a la devolución de la deuda, pero comprometiendo al mismo tiempo al país en cuestión a invertir adicionalmente su importe en gastos educativos, sanitarios, en otros gastos sociales, en infraestructuras básicas, etc. (4). De esta manera la renuncia al cobro por parte de los acreedores tendría pleno sentido político, humanitario, solidario. Seguramente que no le falta a esta postura un muy sólido fundamento.

Para ser objetivos, habría que recordar que el endeudamiento de estos países tuvo dos «culpables»: los bancos acreedores, que prestaron sin tener en cuenta un cálculo prudente de la solvencia de los prestatarios y los beneficiarios de los créditos (empresas por una parte y gobiernos por otro lado) que no canalizaron

(4) En esa línea se sitúa exactamente el gesto de la ONG española Intermón de comprar la deuda mozambiqueña con el gobierno español. 
los recursos hacia inversiones productivas y a los que también les faltó un análisis cuidadoso del futuro.

Las poblaciones empobrecidas no obtuvieron los créditos, ni se beneficiaron de ellos, sin embargo, sí han soportadoel peso del ajuste económico para devolverlos. Aquí es donde se encuentra la injusticia del tratamiento de la deuda: la han «pagado» los que no eran deudores de ella.

En principio, que los acreedores cobren no es indeseable; no hay que olvidar que la insolvencia perjudica no solo al acreedor sino también al deudor. Lo que resulta inaceptable es que la política imprudente de los bancos y de los gobiernos de los PVD (y a veces algo más que imprudentes...) la hayan soportado los ciudadanos que no tenían ninguna responsabilidad en este proceso. Esto es lo que debía haber determinado unos comportamientos de las instituciones internacionales y de las nacionales que tuvieran en cuenta, también, elementos ajenos a la lógica del mercado. 